ORIGINAL ARTICLE

\title{
An investigation of the anger levels of residents: medical compared with surgical disciplines
}

\author{
S Satar, F Cenkseven, O Karcioglu, M Topal, A Sebe
}

Postgrad Med J 2005;81:653-656. doi: 10.1136/pgmj.2004.027334

See end of article for authors' affiliations .....................

Correspondence to: Dr S Satar, Cukurova University, School of Medicine, Department of Emergency Medicine, Balcali, 01330, Adana, Turkey; ssatar@cu.edu.tr

Submitted 28 July 2004 Accepted 1 February 2005
Objective: To evaluate medical and surgical residents' anger levels with regard to the department in which they worked, seniority, sex, satisfaction with their work environment, and the number of nightshifts worked per month. The specific situations and persons at whom residents reacted with anger were also investigated.

Methods: 116 randomly selected residents staffed in a university hospital (62 medical and 54 surgical residents) were enrolled. The trait anger and anger expression scale was used to find out the personal anger levels of each participant. The participants also clarified the persons and situations that made them angry at work.

Results: Trait anger levels were greater in the surgical residents in their first two years when compared with levels of their senior colleagues $(p=0.033)$. Mean trait anger levels were greater in the residents who were not satisfied with their department $(p=0.004)$. Anger levels were not found to be related to the number of shifts per month. Male residents had higher levels of anger than female colleagues $(p=0.019)$.

Conclusion: Residents in clinical sciences seem to have the potential to benefit from a screening process in terms of anger and its subcomponents by means of a tool such as the trait anger and anger expression scale during their residency.
S tress is inherent in medical education. A number of studies put an emphasis on the interrelation of stress and education in medicine. ${ }^{1-3}$ The residency period is also associated with depression, anxiety, ${ }^{14}$ depersonalisation, ${ }^{5}$ anger, and emotional withdrawal. ${ }^{4}$ This process has its impact on the person's attitudes and future career plans. ${ }^{4}$

What are the sources of stress for the resident? The exact causes stem from many factors such as long working hours, limited financial sources, isolation from relatives and friends, etc. Furthermore, high levels of personal expectations, facing an everlasting high tension working milieu, family dissatisfaction with one's working conditions, ${ }^{6}$ sleep deprivation and tiredness, ${ }^{1}$ inadequate support received from supervisors, anxiety of being supervised and evaluated, shortage of leisure times, inadequate coping strategies ${ }^{7}$ also contribute to the stress levels.

It is also probable that stressors contribute to the formation/precipitation of anger. ${ }^{5}$ Anger consists of the interaction between psychological, cognitive, motor, and verbal components of this "normal" and universal feeling at different levels. ${ }^{8}$ In addition, it is able to trigger some behaviour patterns (for example, hostility) that could harm others. ${ }^{9}$ Persons with high anger levels usually experience intense inner conflicts themselves. Furthermore, anger can sometimes preclude accomplishment of necessary professional, physical, educational, and social performances. In some people anger exerts primary negative effects on efficient communication abilities as they preferred physical and verbal means of expression. ${ }^{10}$

Anger is a common phenomenon among residents. ${ }^{11}$ Many studies emphasised the close relation between anger and specialty training. ${ }^{412} 13$ Researchers also reported that the residents were more likely to exhibit emotional upset, ${ }^{14}$ avoidance behaviour, cynicism, ${ }^{4}$ depression, and dependence $^{13}$ than controls.

Medical education is a cumbersome and difficult process to live through. This experience could easily result in a stressful way of living because of short periods of time with family or friends, necessity of long and continuous work hours, undergoing repeated assessments by others, working in a highly stressful milieu. A protracted time course in such an environment will probably increase anger levels of the exposed person.

People are exposed to difficulties in both professional (for example, impaired concentration, poor motivation, malfunctioning physician-patient relationship) and social life resulting from anger itself and also from its expression. Therefore, investigation of residents' anger levels can have vital importance.

Although there are similar data in the literature, our search did not elicit any study related to the anger levels of the residents staffed in and affiliated to medical schools, or to comparison of surgical and medical disciplines. The objective of this study was to evaluate residents' anger levels with regard to be staffed in surgical and medical disciplines, years worked in the discipline, sex, satisfaction with the department they were staffed in, and in relation with the potential anger evoking situations and persons.

\section{METHODS \\ Sample}

A total of 116 (52 women (45.6\%)) randomly selected residents staffed in the surgical $(\mathrm{n}=54)$ and medical $(\mathrm{n}=62)$ disciplines in a university hospital were enrolled in the study. Mean (SD) age of the residents was 28.01 (2.96) (27.4 for women and 28.4 for men) and range was 23-28.

\section{Measures and data collection}

Each participant was asked to respond to the trait anger and anger expression scale, which consisted of two components trait anger and anger expression. Trait anger and anger expression scale has been devised and used to determine anger levels expressed by people and was developed by Spielberger et $a l^{15}$ and subsequently translated and adopted into Turkish by Ozer et al. ${ }^{16}$ The trait anger scale comprised 10 items. Anger expression scale is made up of 
Table 1 Comparisons of the levels of anger noted in residents with regard to surgical and medical departments and seniority-taking two years as the cut off value

\begin{tabular}{|c|c|c|c|c|c|c|c|c|}
\hline & $\begin{array}{l}\text { Surgical } \\
\text { compared with } \\
\text { medical }\end{array}$ & Number & Mean (SD) & $t$ Value & Residency (years) & Number & Mean (SD) & $t$ Value \\
\hline \multirow[t]{2}{*}{ Trait anger } & Surgical & 54 & $21.14(4.49)$ & 0.653 & $<2$ & 63 & $21.40(4.14)$ & 0.216 \\
\hline & Medical & 62 & 20.79 (3.95) & & $\geqslant 2$ years & 53 & $20.43(4.24)$ & \\
\hline \multirow[t]{2}{*}{ Anger-in } & Surgical & 54 & $18.43(5.22)$ & 0.144 & $<2$ & 63 & $17.89(3.43)$ & 0.798 \\
\hline & Medical & 62 & $17.24(3.49)$ & & $\geqslant 2$ & 53 & $17.68(5.37)$ & \\
\hline \multirow[t]{2}{*}{ Anger-out } & Surgical & 54 & $16.49(5.83)$ & 0.088 & $<2$ & 63 & $16.13(5.48)$ & 0.297 \\
\hline & Medical & 62 & $15.07(2.74)$ & & $\geqslant 2$ & 53 & $15.26(2.87)$ & \\
\hline \multirow[t]{2}{*}{ Anger control } & Surgical & 54 & 21.91 (3.97) & 0.734 & $<2$ & 63 & $21.33(3.86)$ & 0.180 \\
\hline & Medical & 62 & $21.66(3.80)$ & & $\geqslant 2$ & 53 & $22.30(3.84)$ & \\
\hline
\end{tabular}

three subcomponents named "anger-in", "anger-out", and "anger control", each consisted of eight items and uses four grade Likert-type self assessment scale. The scale has been reported to have Cronbach's $\alpha$ values between 0.82 and 0.90 , while the corresponding values elicited from anger expression subscales were 0.85 (anger control), 0.76 (anger-in), and 0.74 (anger-out)..$^{15}$ Ozer et $a l^{16}$ reported that the reliability coefficients of trait anger scale was between 0.67 and 0.92 , while those of "anger-out", "anger-in", and "anger control" subscales were between 0.58 and $0.76,0.80$ and 0.90 , and 0.69 and 0.91 , respectively. Significant relations were identified between trait anger and anger expression scale and trait anxiety scale, depressive descriptions list, and anger inventory. Factor analysis showed that the factor components of anger expression scale closely represented those of the original scale.

The respondents also answered questions as to the number of shifts they work a month, the specific situations and people they experienced anger with at work and their wish, if any, to work in another department. The residents were handed a form regarding the anger evoking situations and persons in the working environment. The residents were also free to add situations and persons other than the items listed.

\section{Analysis of data}

The anger levels of the respondents were analysed after grouping them with regard to their sex, departments they were staffed in, the seniority level, their intent to be staffed in another department or not, using the $t$ test in the independent groups. One way analysis of variance was used to compare mean anger levels of the medical and surgical residencies and also those above and below two years of experience in the discipline. Frequency distributions were analysed to determine circumstances and persons the residents had directed their anger at work. Statistical Package for Social Sciences (SPSS) for Windows, version 11.0 was used to analyse data.

\section{RESULTS}

Medical and surgical residents were not found to differ significantly in terms of trait anger-in and anger-out and anger control (table 1). Likewise, there was no significant difference between the two seniority groups (residents in their first two years compared with those who had worked for longer) regarding the same variables (table 1). However, when the same analysis was performed after further grouping the same seniority groups as regards medical and surgical disciplines, the differences were significant for trait anger $(p=0.033)$ and anger-out $(p=0.046)$. To elucidate the source of the difference, the Bonferroni results were scrutinised to elucidate the exact source of the difference. Trait anger levels were greater in the surgical residents in their first two years when compared with figures of their senior colleagues $(p=0.033)$ (table 2$)$.

The difference between anger-in and anger-out levels was not found significant in this context. Anger levels were not found related to the number of shifts per month. Mean trait anger levels were greater in the residents who reported their wish "to complete their residency in another discipline" than in those who preferred to work in the current department $(\mathrm{p}=0.004)$ (table 3$)$.

Only anger-in levels were found to significantly differ between the sexes $(p=0.019)$. Male residents had higher levels of anger-in than female colleagues (table 3). The investigation on specific situations and persons whom residents reacted with anger showed the numbers and frequencies involving each pre-defined cause of anger at work (tables 4 and 5).

\section{DISCUSSION}

Residents' inauguration occurs generally at around the ages of 24 and 26, after six years of medical school in most of the disciplines. This figure is affected mainly by the interval until the specialty examination is passed, the age of attendance to the medical school, and military service in men. Accordingly,

Table 2 Anger levels of residents in surgical and medical disciplines with regard to the seniority in the residency

\begin{tabular}{lllll}
\hline & Number & Mean (SD) & p Value \\
\hline Trait anger & Surgical $<2$ years & 33 & $22.40(4.59)$ & 0.033 \\
& Surgical $\geqslant 2$ years & 21 & $19.17(3.61)$ & \\
& Medical $<2$ years & 30 & $20.30(3.31)$ & \\
& Medical $\geqslant 2$ years & 32 & $21.25(4.46)$ & \\
Anger-out & Total & 116 & $20.95(4.19)$ & \multirow{2}{*}{0.046} \\
& Surgical $<2$ years & 33 & $17.52(6.83)$ & \\
& Surgical $\geqslant 2$ years & 21 & $14.89(3.30)$ & \\
& Medical $<2$ years & 30 & $14.61(2.87)$ & \\
& Medical $\geqslant 2$ years & 32 & $15.50(2.58)$ & \\
& Total & 116 & $15.73(4.49)$ & \\
\hline
\end{tabular}


Table 3 Comparisons of the levels of anger identified in residents as to sex as well as to desire to be staffed in another discipline

\begin{tabular}{|c|c|c|c|c|c|c|c|c|}
\hline & $\begin{array}{l}\text { Satisfied with the } \\
\text { department you were } \\
\text { staffed in? }\end{array}$ & Number & Mean (SD) & $t$ Value & Sex & Number & Mean (SD) & $t$ Value \\
\hline \multirow[t]{2}{*}{ Trait anger } & Yes & 59 & $22.05(4.32)$ & 0.004 & Female & 52 & $20.94(4.42)$ & 0.975 \\
\hline & No & 57 & $19.82(3.77)$ & & Male & 64 & $20.96(4.04)$ & \\
\hline \multirow[t]{2}{*}{ Anger-in } & Yes & 59 & $18.26(4.87)$ & 0.246 & Female & 52 & $16.73(3.60)$ & 0.019 \\
\hline & No & 57 & $17.31(3.85)$ & & Male & 64 & $18.66(4.82)$ & \\
\hline \multirow[t]{2}{*}{ Anger-out } & Yes & 59 & $16.21(5.49)$ & 0.247 & Female & 52 & $15.32(5.96)$ & 0.376 \\
\hline & No & 57 & $15.24(3.10)$ & & Male & 64 & $16.07(2.78)$ & \\
\hline \multirow[t]{2}{*}{ Anger control } & Yes & 59 & $21.63(3.59)$ & 0.675 & Female & 52 & $21.40(3.54)$ & 0.352 \\
\hline & No & 57 & $21.93(4.16)$ & & Male & 64 & $22.08(4.11)$ & \\
\hline
\end{tabular}

the mean age of residency in this study in men is one year more than that in women. The residency period lasts mostly for four years, while in some situations, five.

The first years of the residency process have many inherent challenges such as adaptation into a new working environment, new set of rules, being and feeling inferior to others in the hierarchical order, being told by others what to do, shift work, etc. Many persons could lose professional self esteem under these circumstances. The first year of the residency has been reported to represent the most stressful period with sleep disturbances, long working hours, etc. ${ }^{17}$

Surgical staff have more stressful conditions to bear throughout the residency training. ${ }^{13}{ }^{18}$ We have also found that levels of anger-out and trait anger significantly differed in relation with the discipline and seniority. None the less, multiple comparisons ${ }^{16}$ failed to show significantly differences among the scores of anger-out that reflect the degree of anger directed towards objects encountered in the outer world or to human beings. On the other hand, the trait anger levels that represent the frequency of experiencing subjective feelings such as tension, nervousness, and hate are higher in the residents in their first years in surgical disciplines than that in other disciplines. ${ }^{19}$

Trait anger levels in the residents who actually wish to work in another discipline were found higher than others. Persons who wish to work in another discipline and are not satisfied by the working environment will probably perceive their experiences and environment as stressful and anger evoking. It can also be expected that residents reluctant to perform their daily tasks would live through a restricted social and personal life.
The number of shifts worked per time variable does not have a significant impact on the levels of trait anger and anger expression. This result probably reflects that residents viewed the shiftwork and nightshifts as a part of their daily routine that is inherent in the residency process.

In comparisons based on sex, only the levels of anger-in were found higher in male residents than in female colleagues. Anger-in encompasses the confinement of the perceived anger to some degree and indirect expression of it by means of a variety of mechanisms. ${ }^{16}{ }^{19}$ Women are reportedly more competent in both interpreting verbal and non-verbal expressions of emotions and in conveying feelings to express themselves compared with men..$^{20}$ Therefore, this finding was also expected.

Residents' scores involving trait anger, anger-in, and anger control were higher than the average points. This finding may be attributed to viewing the working environment as anger creating, a tendency to suppress and control their negative feelings by means of certain defence mechanisms such as rationalisation and denial.

The situations most commonly identified by the residents as evoking anger feelings at work were "being asked for things that are not a part of their work", "difficulty in having time and resources to spend for research activities", "interference with or interruption of work related and unrelated schedule by unexpected events", "having to be involved in the care of patients not necessarily seen in an university based hospital", and "feeling of not being treated justly by senior colleagues". The study also showed that the persons that residents commonly direct their anger feelings to were adjunctive healthcare personnel (nurse, technician, etc),

Table 4 Anger evoking events as perceived by the residents at work

\begin{tabular}{lll}
\hline Definition of event & Respondents ( $\mathbf{n}=116)$ & $\%$ \\
\hline $\begin{array}{l}\text { Being asked for things that are not a part of one's work } \\
\text { Difficulty in having time and resources to spend for research }\end{array}$ & 92 & 79.31 \\
activities & 77 & 66.38 \\
$\begin{array}{l}\text { Interruption of work related and unrelated schedule by unexpected } \\
\text { events }\end{array}$ & 67 & 57.76 \\
$\begin{array}{l}\text { Having to be involved in the care of patients not necessarily seen in } \\
\text { a university based hospital. }\end{array}$ & 67 & 57.76 \\
$\begin{array}{l}\text { Lack of physical facilities for rest (for example, no rooms for } \\
\text { resting) }\end{array}$ & 65 & 56.03 \\
$\begin{array}{l}\text { To be exposed to unfair behaviors by the senior colleagues. } \\
\text { To be assaulted/exposed to indecent words by the senior colleagues. }\end{array}$ & 59 & 55 \\
$\begin{array}{l}\text { To encounter with the patients' relatives very often. } \\
\text { To see some residents being treated with some privilege. }\end{array}$ & 52 & 50.86 \\
$\begin{array}{l}\text { Being accused of incompetence in the specially by senior colleagues } \\
\text { To see the residents from other departments accomplishing easier } \\
\text { duties. }\end{array}$ & 46 & 47.41 \\
Being told by the other residents whose experience or "rank" in the & 30 & 43.83 \\
residency is only slightly superior. & 30 & 39.66 \\
Unsatisfactory physical/medical capabilities of the institution & 2 & 29.31 \\
\hline & & 25.86 \\
\hline
\end{tabular}


Table 5 Anger evoking persons as described by the residents

\begin{tabular}{lll}
\hline & $\begin{array}{c}\text { Respondents } \\
\text { (n= 1 16) }\end{array}$ & $\%$ \\
\hline $\begin{array}{l}\text { Healthcare personnel (nurse, } \\
\text { technician, etc) }\end{array}$ & 73 & 62.93 \\
Hospital administrators & 60 & 51.72 \\
Senior lecturers & 52 & 44.83 \\
Patients' relatives & 69 & 59.48 \\
Young lecturers & 38 & 32.76 \\
Senior residents & 29 & 25.00 \\
Patients & 24 & 20.69 \\
Chief resident & 22 & 18.96 \\
Residents of the other departments & 3.45 \\
Interns & 3 & 2.59 \\
Other residents & 2 & 1.72 \\
\hline
\end{tabular}

patients' relatives, hospital administrators, and senior lecturers. This finding may reflect inadequate functioning of adjunctive health personnel, being exposed to repetitive and persistent questioning by the patients' relatives, insufficient support from the directors and administrators, poor psychological support from senior level faculty.

Taking advantage of peer support groups, residents in their first year reportedly show improvement in expressing feelings, gaining awareness of individual and professional problems, and increasing resistance against anger feelings. ${ }^{17}$ Training programmes could be of invaluable help both individually and professionally, if specifically devised to improve skills in dealing with anger, stress management, and communication skills. These kinds of programmes are thought to help in acceptance of the common inevitable nature of certain difficulties encountered in the training process, gain an internal view to recognise problems experienced, and learn how to cope with them.

\section{CONCLUSION}

Residents in clinical sciences seem to have the potential to benefit from a screening process in terms of anger and its subcomponents by means of a tool like the trait anger and anger expression scale during their residency. Such an easy to use monitoring device would help in disclosing minor conflicts, provide insight for the residents, and help in scheduling timely interventions to prevent adverse outcomes. In addition, the results of the study may augment identification of the residents harbouring high risk for high levels of anger and specify the situations and persons with whom they experience anger.

\section{Authors' affiliations}

S Satar, M Topal, A Sebe, Cukurova University, School of Medicine, Department of Emergency Medicine, Adana, Turkey

F Cenkseven, Cukurova University, Faculty of Education, Department of Educational Sciences

O Karcioglu, Dokuz Eylul University, School of Medicine, Department of Emergency Medicine, Izmir, Turkey

Funding: none.

Conflicts of interest: none.

\section{REFERENCES}

1 Butterfield PS. The stress of residency. A review of the literature. Arch Intern Med 1988;148:1428-35.

2 Hainer BL, Palesch Y. Symptoms of depression in residents: a South Carolina family practice research consortium study. Acad Med 1998;73:1305-10.

3 Sahpiro SL, Shapiro DE, Schwartz GER. Stress management in medical education: a review of the literature. Acad Med 2000;75:748-59.

4 Martin AR. Stress in residency: a challenge to personal growth. J Gen Intern Med 1986; 1:252-7.

5 Michels PH, Probst JC, Godenick MT, et al. Anxiety and anger among family practice residents: a South Carolina family practice research consortium study. Acad Med 2003;78:69-79.

6 Jellinek MS, Todres ID, Catlin EA, et al. Pediatric intensive care training: confronting the dark side. Crit Care Med 1993;21:775-9.

7 Levey RE. Sources of stress for residents and recommendations for programs to assist them. Acad Med 2000;76:142-50.

8 Sharkin BS. The measurement and treatment of client anger in counseling. $J$ Counsel Dev 1988;66:361-5.

9 Howells K, Day A. Readiness for anger management: clinical and theoretical issues. Clin Psychol Rev 2003;23:319-37.

10 Deffenbacher JL, Lynch RS, Oetting ER, et al. Anger reduction in early adolescents. J Counsel Psychol 1996;43:149-57.

11 Champell DC, Price JL, Newton WL. Understanding anger in residents. Fam Med 2000;32:85-6.

12 Ford CV, Wentz DK. The internship year: a study of sleep, mood states, and psychophysiologic parameters. South Med J 1984;77:1435-42.

13 Veldnez HC, Scott KK, Dennis JW, et al. Impaired residents: identification and intervention. Curr Surg 2002;60:214-17.

14 Cook DJ, Liutkus JF, Risdon CL, et al. Residents' experiences of abuse, discrimination and sexual harassment during residency training. Can Med Assoc J 1996;154:1657-65.

15 Spielberger CD, Jacobbs G, Russell S, et al. Assessment of anger: the statetrait anger scale. In: Butcher JN, Spielberger CD, eds. Advances in personality assessment. Vol 2. Hillsdale, NJ: Erlbaum, 1983:45-54.

16 Ozer AK. [A study on the cognitive mechanisms underlying the tendency to anxiety, anger and depression] (In Turkish). Turk J Psychol 1994;9:12-25.

17 Alexander D, Skinner B. A pilot study using the group environment scale to evaluate first-year resident support groups. Fam Med 2002;34:732-9.

18 Bunch WH, Dvonch VM, Storr CL, et al. The stresses of the surgical residency. J Surg Resid 1992;53:268-71.

19 Özer AK. [A preliminary study of the trait anger (T-anger) and anger expression scales] (In Turkish). Turk J Psychol 1994;9:26-35.

20 Goleman D. Emotional intelligence: Why it can matter more than IQ. New York: Bantam Books, 1997:75-92. 